\title{
The function "Chief happiness officer" and the double performance Reality and perspectives in African countries Case of B2S Morocco
}

\author{
Hajer NAJEH \\ Department of management, Assistant professor of management, University of Gabes - Tunisia
}

\begin{abstract}
Happiness at work is a major issue, which is now widely acknowledged. However, this factor needs to be taken into account in a more in-depth approach in the new insights that have been recently generated. Indeed, it is often the motivational factors derived from the theories of organizations applied in large companies that are cited as an example. More than merely an overview of these practices, other studies focus on the inadequacy of these factors to achieve the targeted motivation. It then becomes pertinent to question the analysis of the degree of employee satisfaction by integrating happiness as a new motivating factor. The main objective of this paper is therefore to develop a heuristic model that can be used to examine the articulation of classical as well as atypical motivational factors with social and economic performances, while introducing the position of the Chief happiness officer as a stimulant to these performances.
\end{abstract}

Keywords:

Atypical Motivational Factors, Chief Happiness Officer, Social Performance, Economic Performance.

\section{Introduction}

Based on the United Nations report (2012) «A range of studies carried out by psychologists, economists, surveyors, sociologists and others have demonstrated that happiness, albeit a subjective experience, can be objectively measured, evaluated, correlated with observable brain functions, and linked to the particular characteristics of the individual and society» 
Research has shown that employees are constantly searching for happiness, but they are not aware of how to achieve it. It is within this framework that this current research is being carried out.

Thus our central research question is as follows: which perspectives can be offered by the role of a Chief happiness officer in enhancing the social and economic performance of companies in African countries?

The objective is to stress the importance of the issue and the pressing need for executives and HR managers to raise this concept to the top of their priorities.

Thus, this article seeks to develop a heuristic model that examines the importance of the role of the Chief happiness officer in generating happiness at work and boosting performance. The first part of this paper proposes a state of the art on the human factor and the raison d'être of a Chief happiness officer. The second section describes the progressive development of a model, which will be subsequently, in the third section, tested on a Moroccan company in the telemarketing field.

\section{State of the art}

In general, happiness is a long-lasting state of plenitude, satisfaction or serenity, a state of well-being and balance of the spirit and body, free from any form of suffering, stress, anxiety and perturbation. Several factors can be involved to attain this state, particularly at work.

\section{Motivating factors and happiness:}

First and foremost, it is necessary to distinguish between the motivating factors, as defined by management researchers and the new missions of a Chief happiness officer that allow stimulation of employees' motivation. For this purpose, we will initially further define happiness at work by adopting the motivation theories.

\section{Happiness at work: a motivating factor}

\section{- $\quad$ Theories of motivation at work}

Based on the theories of organizations as reflected in the management books, several motivating factors have been identified. Since the 1990s, the classics have highlighted remuneration as the most important motivating factor. Taylor, Fayol or Weber, considered the latter as the only motivating factor for lazy and irresponsible staff. This approach was then criticized by other theories that have emerged throughout the years. Indeed, in 1929, the school of human relations was founded by Elton Mayo highlighting social need as a motivating factor at work. Mayo and his collaborators conducted their experiments in the "Howthorne" factory specialized in assembling telephone sets. They eventually came to the conclusion that social status and teamwork promote job satisfaction and increase employees' motivation. However, this is not yet the level of satisfaction necessary to achieve the motivation of the latter, as Maslow founded his approach based on the famous hierarchy of needs in the 1940s (Figure 1). The latter are hierarchical and complementary to generate satisfaction. This approach was later adopted by Mc Gregor (1960) and Herzberg (1978) to support their approaches based on participatory management. 


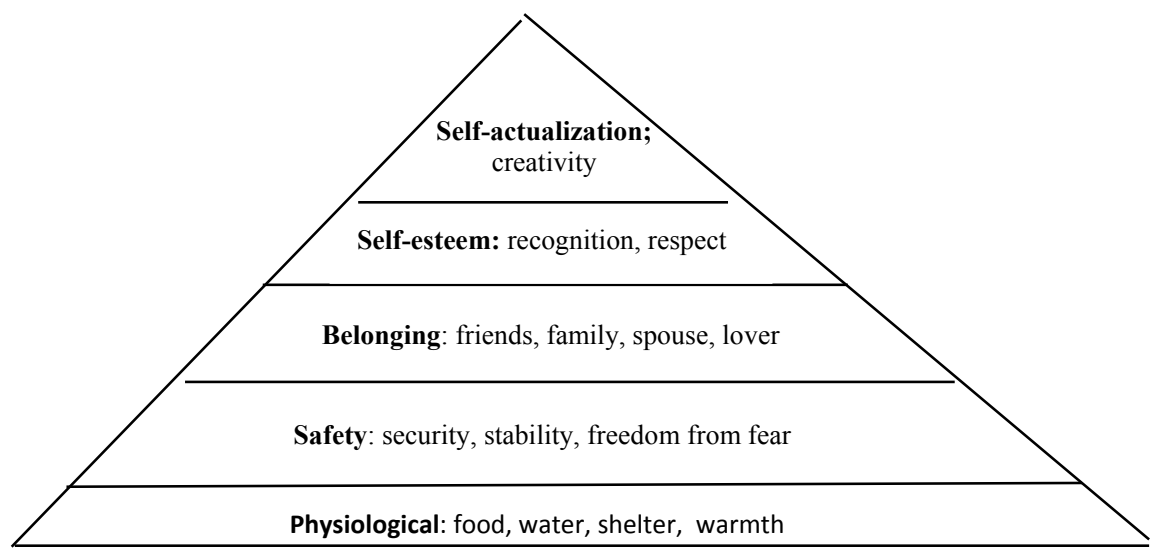

Figure 1. Hierarchy of needs

Source : PLANE, Jean Michel (2013): «Théorie des organisations», 4eme édition, Dunod, Paris, p 38.

- $\quad$ Atypical motivational factors: the example of Google Company

Motivational factors, which have emerged from organizational theories, have proved their ineffectiveness in stimulating employees' motivation and enhancing their performance. Indeed, the demotivation of employees is a reality in society, besides the increasing number of work-related problems. As it is the case with France Telecom and many other companies, the staggering number of suicides associated with working conditions has led some company executives to reflect closely on this issue. The search for other methods and techniques to motivate employees is becoming a necessity; it is the atypical factors that generate happiness (Mucha, 2010). This can be illustrated with the example of Google, which is one of the pioneers of Internet search engines and is highly innovative. Google differentiates itself in the way in which it gets its employees involved in the workplace. This is particularly the case in its European engineering centre located in the south of Zurich, Switzerland, a centre dedicated entirely to research and development. This $12,000 \mathrm{~m}^{2}$ building employs 500 engineers, aged roughly 30 on average, from 40 different countries, who work daily in the world's largest Internet Company. In this enterprise, working conditions are described as exemplary, a commitment of the company, where happy employees work harder and better. In fact, all efforts are geared towards creating a pleasant working environment for employees, staff work in open-space areas that are decorated in a way to remind them that Google is particularly concerned about the comfort of its employees. Each floor has a specific theme: beach, jungle, football.... Throughout the whole the building, "bubbles" are used for isolation, either single or pair. They take the form of cable car cabins or flying saucers depending on the floor. Each floor is equipped with a mini cafeteria offering a free and full-service menu of fresh fruit, cakes and drinks. Employees are encouraged to access the area at any time they feel the need. According to Mathias Gref, Head of Communication at the Zurich site, «The ultimate goal is that the employee solves the problem he/she is facing. If he/she has to spend 20 minutes relaxing in an armchair drinking coffee and looking at the surrounding mountains while trying to find the solution, then there's nothing to worry about». In this building, there are also areas for games, massage and relaxation with music, saunas, a hairdresser and even a nursery for children. So many different measures for the well-being and motivation of employees are implemented. Indeed, the company endeavors all its efforts to encourage employees to continue working in the company, but the main objective of the company is to earn more money by having employees always more motivated and therefore always more efficient. Despite the fact that some Google employees admit that there is a lot of work and pressure, these atypical working conditions would make it difficult for them to consider working elsewhere. 
All these different factors combined together ensure that happiness is attained. However, a coordination and organizational effort must be made to achieve the latter. Thus, a function of "Chief happiness officer" has recently emerged in the structures of organizations, most notably the American and French ones.

- The function of a «Chief happiness officer»

First introduced in America, with the company "Google", the function of "Chief happiness officer" is designed to ensure that employees enter the workplace happily, and to create a pleasant working atmosphere in order to retain them. The profession of Chief happiness officer is not just a gadget, but a real challenge for companies since it aims to enhance employees' productivity.

It is a very innovative profession that is nowadays emerging in organizations where the basic belief is that an employee who feels comfortable at work is twice more productive.

\section{- $\quad$ Missions}

By ensuring the well-being of employees at work and implementing a positive and serene work culture, a Chief happiness officer has several missions.

$\mathrm{He} /$ she ensures the development of a good working environment by maintaining and making the spaces more pleasant, as well as identifying the problems experienced by employees and finding appropriate solutions. His/her role is to organize breakfasts, lunches, aperitifs or parties on behalf of the company, as well as to offer in-company leisure activities: yoga, karaoke, relaxation therapy, and massage sessions... he/she is in charge of welcoming newly recruited employees and ensuring their integration, which is one of the crucial steps in the recruitment process. By pursuing the primary mission which is to create happiness, the Chief happiness officer often devotes particular importance to certain personal problems. His/her communication role is demonstrated in the organization and scheduling of internal communication by encouraging and creating better relationships between employees.

The function of the Chief happiness officer, located halfway between communication and HRM, also includes working on strategic issues of the company: implementation of new digital tools, working hours, teleworking, individual interviews, training..., for the purpose of creating well-being, he/she also offers specific services to staff such as subscriptions to a fitness centre, concierge services, etc.

\section{- $\quad$ Required qualities}

The analysis of the function of the Chief happiness officer reveals certain qualities required to hold this position. As an event creator and mediator, he/she must be creative, dynamic and always good listener to others. he/she must sharpen his/her observational and analytical skills to accurately detect the needs of employees. Organizing events must be he/she second talent. For this reason, a Chief happiness officer must necessarily have a sound organizational spirit and a rigorous approach. To succeed in this mission, enthusiasm, good temper and high sense of humor are the perfect characteristics of a Chief happiness officer.

Regarding the required training for this position, many Chief happiness officers are from the communication or human resources sector.

\section{Initial posture and priorities of HRM}

Work-life quality is an increasingly significant issue within companies. The creation of happiness at work will depend on the willingness of all companies to adopt this approach by offering their employees services designed to improve their well-being at work. This can be confirmed by Thiran 
(2012) who states that: « Happiness at work is first and foremost a managerial concern. It is up to the manager to ask himself the question of to what extent he feels concerned by this issue and ready to integrate it into his priorities. »

The management style adopted is a prerequisite for spreading this happiness. Indeed, if the style applied within an organization is an authoritarian one, it must be replaced by a participatory management style. The latter will highlight the importance of the human being and raise the issue of his requirements and motives. From this perspective, human value must be one of the major priorities of the company's HRM strategy. It is also necessary for executives to change their beliefs and spread a culture of happiness within the organization (Lahlou, 2017).

\section{The culture of happiness: a stimulus for employees' motivation and performance}

From a perspective of creation of happiness, Lahlou (2017) states that: « Human Resources managers, executives and directors must change their strategies and integrate a culture of happiness and wellbeing into their companies». Thévenet (2006) defines corporate culture as a set of shared values, rites, myths, symbols and the history of the organization. Based on this definition, we can highlight the following components of corporate culture: Values: these are behavioral codes (operating values) that have defined the company's history and management practices and the declared values (those that appear in the company's discourse). Symbols: these are signs (logo, style, dress...) loaded with cultural information that are linked to core values. They also serve as communication elements both internally and externally. Myths: narratives, anecdotes, imaginary or symbolic stories that are shared within the company (e.g. the myth of upward social mobility). The company's history: The advantage in understanding the company's history is to identify its culture. It is therefore necessary to analyze it in order to grasp its main phases of evolution and decisions, using fields of interest that may refer to the company's activity and products, the technologies used, the internal and external structures applied and the strategies adopted. This analysis will be used to objectively determine what the society has retained from the company's history. Heroes: these are generally the founders, charismatic executives who are part of the company's myths and who are a benchmark for employees. Rituals: specific behaviors stemming from the habits and practices developed in the company. Taboos: these are the prohibitions in an organization (events, situations that should not be addressed...).

Proponents of the cultural approach highlight the role of culture in influencing the efforts within an organization. Thus, to create happiness it is primarily essential to implement a culture of happiness. In other words, to spread values, symbols, and rituals... valorizing happiness as a crucial and primordial factor. The intention is to raise this awareness in employees' minds in order to highlight it.

\section{Optimism}

«Optimism is the root for the collective establishment of a positive attitude at work» Stated by Bormans (2012), highlighting a clear link between happiness and optimism.

Optimism is one of the essential conditions for achieving happiness. As it is defined by Fiaux (2007) «the philosophical principle according to which everything is for the best in the world», in practice the author adds that optimism is «to see only the most attractive and best side of people and things» .

This optimism fills those who practice it with courage, confidence, good humor, as well as sympathy, kindness and respect for the people with whom they are in contact. This is why optimism is beneficial, not only for us, but for those with whom we live. When our thoughts, our attentiveness, our vision come into action, they transmit an energy loaded with an invigorating principle; this energy has a retro-reflective action (in return) on us. We notice that there is a link between happiness and optimism on one hand, and a link between happiness and optimism and action on the other. In fact, 
optimism brings both joy and happiness that are vital elements in motivating and encouraging people to work, which boosts productivity. This relationship is validated by Smiles (1859) who states that: « The most productive work is the one that is done with love, the one that comes out of the head and hands of a man with a joyful heart.». We must therefore develop optimism and get used to identifying only the beautiful sides of human beings and things. In fact, according to Smiles (1859): «We can, indeed, get used to seeing everything beautiful, just as we can get used to seeing everything ugly». It is through the willingness, which we possess, that we can cultivate the practice of happy thoughts. It is also possible to cultivate in some, men and women, a natural happiness, a straightforward personality, a pleasant disposition of the spirit, sources of happiness and perfection (Fiaux, 2007).

The availability of diverse motivational factors can certainly contribute to improving the well-being of an employee; however, the latter can only be happy if he/she is able to perceive things in a positive way. Thus, there is an evident link between happiness and optimism. On the other hand, a research carried out on the happiness of non-executive staff indicates that the key to the happiness of this professional category lies in the high quality of optimism they have at their disposal.

\section{Happiness and performance}

According to the survey conducted by StepStone in 2012, the results have demonstrated that there is a close connection between happy employees and a set of organizational benefits: greater devotion, better talent attraction and less turnover and absenteeism. A thriving company has a distinct competitive advantage over other companies where the level of employees' happiness is relatively unsatisfactory. In this regard, happy employees earn more money, enjoy more promotional opportunities, provide work of higher quality, perform better, make fewer mistakes and are more productive and dedicated.

Furthermore, in a conference focusing on happiness at work held in Toulouse Business School Casablanca in March 2017, one of the guests stated that: «According to international studies, happy employees are twice less sick, 6 times less absent, 7 times more loyal to their employer, 31\% more productive and 55\% more creative». This highlights an obvious link between happiness at work and performance. The latter is twofold; given that a happy employee becomes more motivated when the various motivational factors are combined to ensure his/her satisfaction. As already mentioned, these different factors are interrelated with happiness, which is also a motivating factor. The immediate result will be primarily on social performance, which will improve thanks to the increase in labor productivity. This will subsequently have an impact on the company's economic performance.

We acknowledge the crucial role played by the Chief happiness officer, who is perceived as an intermediary between human needs and those of the company. In fact, by creating a good working atmosphere, the Chief happiness officer helps to attract the company's most talented employees for a longer period of time. This allows employers to reduce costs in the recruitment and training process and thus to make savings. It is agreed upon that a happy employee is less likely to be sick than an employee who drags his feet to work every morning.

\section{Proposal of a heuristic model}

A model and a set of questions make it possible to verify the existence of the various conditions favorable for the creation of happiness at work: the four dimensions, the initial posture, and the Chief happiness officer (figure 2). 


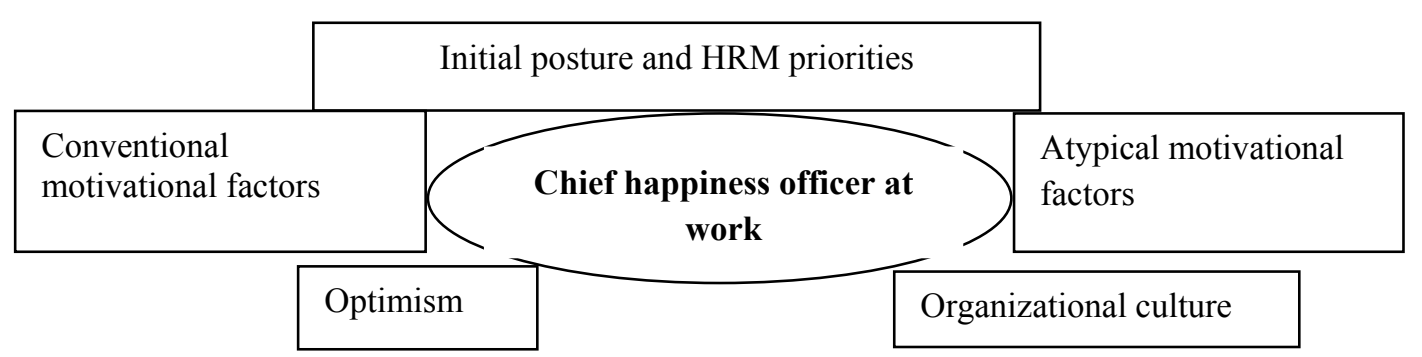

Figure 2. An analysis grid of the factors of happiness at work

- First, the initial posture and strategic priorities: is the employees' happiness really a strategic priority? If so, are the HR policy developers in the organization ready to change their approach?

- Then, four key dimensions: are the motivational factors that are established by organizational theories, and those of an atypical type available? Is there a certain degree of optimism among employees to direct their thoughts towards a more positive orientation? Does culture influence attitudes to this extent?

- Finally, does the Chief happiness officer do his job as a mediator and local coordinator to implement such processes?

\section{Research methodology:}

The objective of our research is to shed light on the position of «Chief happiness officer» and his/her role in enhancing employees' performance. We deem it important to prove that this function, which is still totally ignored in African countries, is of major importance, because it generates a dual performance: social and economic.

Therefore, our methodological approach consists of two phases: The first part consists in conducting a quantitative study among employees working in Tunisian companies. The objective is to evaluate the extent to which these employees are happy at work, in the absence of a Chief happiness officer.

The collected data and observations come from a questionnaire survey conducted among a sample of 100 executives and employees in Tunisia, who work for governmental, semi-governmental and private companies (or institutions or agencies).

The second part consists in conducting a qualitative study, in order to test our theoretical model and illustrate the crucial role played by the Chief happiness officer, recruited for the first time in Africa, in motivating workers. This is B2S, a call center located in Morocco.

All data and observations collected to constitute the B2S case are drawn from several primary and secondary sources: - primary: from 2014 to 2017; a collection of presentations given by the Chief happiness officer at B2S in several professional organizations; - secondary: a collection of all the events held by the Chief happiness officer, published on the Facebook page of B2S Morocco and in various other magazines. Each of them resulted in a thematic content analysis (Bardin, 1991 ; Hubermann \& Miles, 1996 ; Romelaer, 1999). The process started with the constitution of themes. We started from different themes from our review of literature. The table $n^{\circ} 1$ presents the excerpts of the dictionary of themes relating to the main aspects which interest us here (The missions of the Chief happiness officer, Motivational factors and atypical factors, social performance). 
Table 1 . Themes Dictionary (extract on the main themes)

\begin{tabular}{l} 
Themes \\
\hline Initial posture and HRM priorities: \\
The importance of HRM in the strategic policy of the firm. \\
\hline Chief happiness officer at work: \\
Elements on the main missions of the chief officer at work (compensation, communication, organization of \\
breakfast, welcoming newly recruited employees and ensuring their integration, devoting particular \\
importance to certain personal problems...)
\end{tabular}

\section{Conventional motivational factors:}

Salary, social need, security need, need to esteem, self-realization

\section{Atypical motivational factors:}

Other methods and techniques to motivate employees is becoming a necessity; it is the atypical factors that generate happiness (gym, games room, organization of parties or contests...)

\section{Optimism:}

Contains the answer to this question: "How to apprehend the future ?"

\section{Organizational culture :}

Elements on the components of organizational culture (symbols, the company's history, rituals)

\section{Performance :}

social performance (devotion, talent, attraction, turnover and absenteeism)

economic performance (work productivity, costs in the recruitment and training process)

\section{Empirical study:}

As mentioned above, our empirical study is based on two stages: the evaluation of workers' happiness in Tunisia and the proofing of the theoretical model through the case study of the «B2S ».

\section{Evaluation of employees' happiness in Tunisia:}

In order to assess the degree of happiness among Tunisian workers, we conducted a questionnaire survey among a sample of 100 employees belonging to private and public companies.

Table 2. Description of the sample

\begin{tabular}{ccc}
\hline State-owned entreprises & Semi-state entreprises & Private entreprises \\
\hline 48 & 2 & 50 \\
\hline
\end{tabular}

The analysis of results shows that:

- $95 \%$ of the respondents stated that they are very unhappy at work, $100 \%$ of whom are in the state sector (table 2). These interviewees reported an almost total absence of atypical motivators (sports halls, janitorial services, etc.). Only the training seminars were mentioned as existing factors within their organizations. 


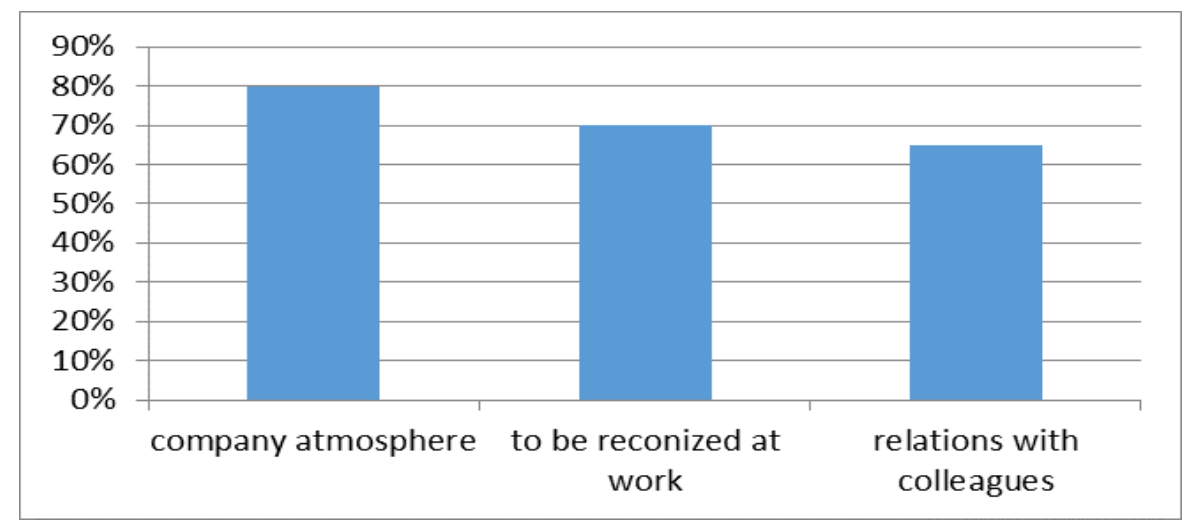

Figure 3 . The key motivating factors nonexistent in organizations

- $80 \%$ of the workers who were interviewed claimed that happiness is the key to success and not the opposite. (Figure.3). They classify the company's atmosphere as the leading factor of happiness within Tunisian organizations. However, this factor is still absent in organizations. Along with being recognized at work and the relationship with colleagues which are classified second and third respectively.

According to the survey, these companies motivate their staff through remuneration and involvement.

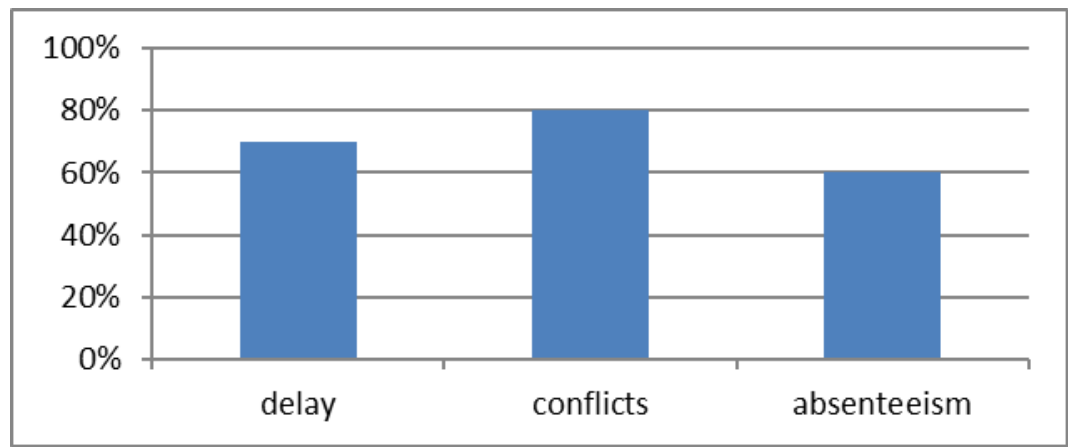

Figure 4. The most current indicators of malfunctions

The absence of happiness in Tunisian companies is behind some of the malfunctions detected. In fact, delays, absenteeism and conflicts are the most significant indicators of malfunction identified by the interviewees (Figure 4).

These statistics reinforce Badri's (2017) observations regarding the impact of happiness on employees' motivation and productivity.

Due to the inadequacy of the motivational factors derived from the organizational theories, it is therefore necessary to suggest other factors that must be taken into consideration within Tunisian organizations in order to attract and retain workers, as in the case of "B2S".

Testing the model: B2S, happiness at work «a possible mission»

We therefore propose to test the analysis model that has been developed in order to study the approach of a company adopting an explicit policy of employees' retention and valorization, which is the « B2S » case. Based on the strategy of its HRM linked to general policy (3.2.1), « B2S » unevenly embodies the key components of happiness at work (3.2.2), and gives rise to tensions to be observed (3.2.3). 


\section{A first in Morocco: a position of « Chief happiness officer»}

The difficult nature of working in call centers and the high turnover rate have encouraged B2S managers to look for new techniques to retain their employees. Indeed, since managers are convinced of the crucial importance of human value and its role in creativity, they strongly believe in the need to innovate the methods used to motivate their employees. A new factor is highlighted, namely "happiness at work", which thus becomes closely linked to classic motivation. Consequently, in recent years, we have thought of creating a new function in the organizational structure of B2S, namely "Chief happiness officer". It was in 2014 that the position was held by a young woman whose qualifications meet the requirements of the position. The latter requires its holder to be sincere, creative, to enjoy teamwork and most importantly to be "happy".

The person in this position is Mrs. S. F., "Chief happiness officer» at B2S. The young manager is keen to define her mission as being «halfway between HR and communication». For her, «Happiness at work is a flow of positive emotions. However, my job is not about clowning around to make employees laugh, but rather about influencing the positive psychology and personal development of employees.»

It is on the basis of her speech and the research we have conducted on the case of B2S that we will explain, in the following, the different factors and conditions necessary to generate happiness at work.

The missions of the «Chief happiness officer» at B2S:

In response to the question on the daily practices of her mission, S. F explains that she ensures the existence of a serene and collaborative climate among the employees and proposes multiple activities to create conviviality and consolidate team spirit. In this regard, she ensures that a good working atmosphere is created and that a serene and positive work culture is established. She ensures the maintenance and conviviality of the working spaces. She seeks to identify the difficulties experienced by employees and find appropriate solutions. She offers what she calls "after f'tour", which consists in organizing evenings offered by the company. She also organizes contests to win gifts such as the random draw offering participating employees the chance to win cars.

The Chief happiness officer at B2S is also interested in the psychological state of employees; she provides them with relaxation activities to manage their stress. She welcomes the newly recruited employees and ensures their integration. She, also, organizes and plans internal communication by promoting better relationships among employees, and always strives to create links between them. To do this, competitions are organized such as "happy friends' day" which is held to make employees win a party with friends.

Furthermore, while taking full advantage of her skills in HRM, the Chief happiness officer is responsible for strategic elements of the company such as the implementation of new digital devices, working hours, teleworking, interviews, training, etc...,

Finally, always keeping in mind the satisfaction of employees, the Chief happiness officer offers specific services to employees: such as subscriptions in a sports hall.

Based on the responsibilities of the Chief happiness officer at B2S, we will, in the next section, test our theoretical model by verifying the existence of the key factors that generate happiness. One of the conditions has already been verified, namely the existence of the Chief happiness officer.

\section{Motivational factors and atypical factors that are inseparable:}

The analysis of all the missions of the Chief happiness officer allowed us to detect a set of motivational factors granted to employees. These are essentially remuneration, communication and teamwork. These factors, derived from organizational theories, increase employees' motivation but do 
not generate happiness. It is therefore essential to associate them with atypical motivational factors that are essential to create a pleasant atmosphere among B2S employees.

Compensation: apart from salary, the company also offers several fringe benefits to all employees. The technique adopted to grant these perks arises from the innovative ideas proposed by the Chief happiness officer, including mini-contests and draws offered to telemarketers to win cars.

Teamwork and communication: human relations is highly valued and considered as one of the priorities of B2S. Some values, such as friendship, are appreciated in order to stimulate communication and group work. To do this, new techniques are used. This includes, for example, organizing competitions called "special happy friends' day". It is a special event organized to help employees win an evening with friends. The rule of the game is to send a "selfie" of a group of friends to B2S; the photo will then be shared on the company's facebook page. The winning team will be the one with the most shared photo. This technique helps to strengthen the bond between employees and create a good working environment and above all a favorable social atmosphere. This helps to spread joy among the employees of B2S.

Atypical motivational factors may equally be features in evening parties organized as part of "after f'tours" programmes, or in subscriptions in sports halls granted to certain employees who are the most talented in physical activity, or even sessions of stress management and relaxation organized within the company.

\section{A culture of happiness:}

One of the most essential tasks of the Chief happiness officer is to spread a culture of happiness among the entire B2S team. The main objective is to highlight happiness and to raise employees' awareness that it is a vital factor in their development. Happiness is perceived as a stimulus for growth and performance. In this regard, a close link between happiness and work emerges. Indeed, these two will enhance an individual's performance. Two values are thus inseparable, namely a value of happiness and a value of work. Several techniques are used to disseminate these values; this is particularly noticeable in the daily messages sent to the B2S employees, through the facebook page or the posting inside the company. Indeed, a very specific language related to happiness is often used such as «happy B2sians», «happy Monday», «happy week end», «happy people», «happy thinkers»... This will contribute to the establishment of this culture of happiness in the consciousness and thoughts of B2S employees.

As mentioned above, this value must be inextricably linked to the value of work, in other words, the objective is simply to work and have fun at the same time. It is a way of taking things seriously in the face of means of fulfillment, which must motivate the individual to work. Thus, among the messages that have often been circulated is the following: «At B2S, we work while having fun» .

\section{An optimistic staff:}

The overriding objective of the Chief happiness officer at B2S is to promote positive psychology. As a consequence, efforts are being made to spread optimism which is one of the prerequisites for happiness and success. This can be deduced from all the events scheduled by Mrs. S.F., in particular the sessions of stress management organized within the company. Indeed, being fully aware of the detrimental effects of stress on employees' mood and consequently on their performance, the Chief happiness officer seeks to manage it and generate a positive mood that is a source of optimism. This will definitely has an impact on the performance of employees at B2S. 


\section{Happiness and performance:}

«Whoever sows happiness reaps performance: a happy employee is 4 to 5 times less absent than an unhappy employee. »

Mrs. S.F. is therefore convinced that happiness is learned and transmitted and that work discomfort is costly for the company, as statistics have confirmed. Indeed, by taking the absenteeism rate as a performance indicator, the Chief happiness officer acknowledges a significant decrease. From this perspective, happiness at work has a positive impact on the psychology and performance of employees, and succeeds in attracting and retaining them. Such social performance will have, as the literature suggests, its positive impact on the economic performance of "B2S".

\section{Conclusion}

Beyond the rigorous incantations on the importance of motivational factors related to work in general and productivity in particular, the integration of happiness at work as one of these factors remains an ongoing project. Indeed, even if it is obvious that motivation must involve all employees, and even if we currently have a well-enriched brochure of "good practices", shaping and implementing happiness as a stimulant of social and economic performance can only be achieved by reconsidering certain "standard" practices and especially by the systematic coherence of key-dimensions. We have therefore sought to fulfill in part the need that is emerging in the literature: to have an integrated heuristic model that allows us to question the coherence of happiness with performance, by first proposing six major themes for further examination and enriching them with the help of an exploratory case. Now it remains to further refine this model through field-based investigations, in order to develop real hypotheses on the implications of the dimensions we have identified.

To conclude, happiness at work remains a relative, but not impossible, notion. Happiness is definitely to be found in the positivity and spirit of people, but in a more professional context, it is also the responsibility of managers who are convinced that happy employees tend to be more involved, more loyal, more creative and more productive than unsatisfied employees.

\section{References}

Badri, S. (2017), «Il est où le bonheur au travail ? », Le Matin, 02 Avril, p.1.

Bardin. L. (1991) Réed. « L'analyse de contenu », coll. Le Psychologue, PUF.

Bormans, L. (2012), World Book of Happiness, international editions.

Dupre, G. (2017), Le Bonheur au travail outil de transformation au cœur des organisations, Revue Personnel ANDRH, Mai,.

Fiaux, J. (2007). Comment réussir dans la vie ? La volonté bien éduquée peut commander la destinée, Edition, (iStockphoto.com/ Lev Mel.

Huberman. M. \& Miles M. (1996) Réed. « Analyses de données qualitatives », De Boeck université.

Lauraa, M. (2010), La motivation des salariés et la performance dans les entreprises, Gestion et management.

Plane, J.M. (2013), Théorie des organisations, 4eme édition, Dunod, Paris.

Romelaer. P. (1999) « La méthodologie de l'entretien », Mimeo.

Smiles, M. S. (1859), Self-help, Boston : Ticknor and fields, in Fiaux, J (2007), Comment réussir dans la vie ? La volonté bien éduquée peut commander la destinée, . Edition, iStockphoto.com/ Lev Mel.

Thevenet, M. (2006), La culture d'entreprise, 5ème édition, PUF, Paris.

Thiran, Ch. (2012), Comment créer les conditions du bonheur ?, Peoplesphere nº 162 . Avril. 